\title{
A ÁGUA DO SOLO E O SOMBREAMENTO DOS CAFEZAIS NA AMERICA CENTRAL
}

\author{
Conraci M. Franco (1) \\ Engenheiro agrônomo, Secção de Fisiologia e Alimentação de Plantas, Instituto \\ Agronômico de Campinas
}

1 - INTRODUÇÃO

Em publicações anteriores $(\mathbf{3}, \mathbf{4})$, mostramos que, nas condições da maioria dos cafèzais sombreados de São Paulo, há grande concorrência em água do solo entre cafeeiros e árvores de sombra. De acôrdo com dados obtidos, essa concorrência tem sido o fator limitante no sucesso da prática do sombreamento em nossos cafèzais. De fato, os dados têm mostrado que a umidade do solo no interior de um cafèzal sombreado, após dois ou três meses de sêca, se acha no limite denominado "wilting point" $\left({ }^{2}\right)$, às vêzes, até a um metro de profundidade. Isto significa que grande parte das raízes, ou mesmo a maioria delas, dependendo do desenvolvimento do sistema radicular, que varia com o tipo de solo (6), já não encontra água para absorver.

Em cafèzais cultivados ao sol, essa concorrência não se mostra tão séria, porque nêles não há o abundante sistema radicular da árvore de sombra a absorver também grandes quantidades de água do solo.

Os cafèzais sombreados dos outros países cafeicultores americanos estão, na maior parte, situados em zonas de boa distribuição pluviométrica, não havendo, por isso, concorrência em água entre árvores de sombra e cafeeiros. Esta é a situação dos cafèzais da Colômbia, por exemplo.

Entretanto, na América Central, há cafèzais sombreados em zonas com distribuição pluviométrica semelhante à do planalto paulista e, às vêzes, com sêcas ainda mais prolongadas, como é o caso da República de El Salvador.

A fim de fazermos estudos sôbre a umidade do solo na época sêca, principalmente determinações de "wilting point" para o cáleulo de água

(1) A execução do presente trabalho foi possivel graças à colaboração do Instituto Interamericano de Ciências Agrícolas de Turrialba, Costa Rica; do Servicio Tecnico Interamericano de Cooperación Amricola (STICA), Costa Rica; do Centro Nacional de Agronomia e Federación Cafetalera Centro-America y Mexico em El Salvador.

A todos os funcionários das instituiçóes acima referidas, que, direta ou indiretamente, nos auxiliaram na elaboração dêste trabalho, aqui deixamos consignados os nossos agradecimentos.

Fim virtude da dedicaçăo que nos revelaram, deixundo de lado seus afazeres, para que pudessem acompanhar-nos pessoalmente a inúmeros cafèzais de onde retiramos amostras de solo, ajudando-nos ainda nesse mister com visível boa vontade, durante muitos dias, devemos também aqui expressar especiais agradecimentos às seguintes pessoas: Eng. ${ }^{\circ}$ Agr.o Victor Manoel Perez, de Alajucla, Costa Rica; Sr. Tomaz Vilanova, de Santa Tecla, El Salvador; Eng..$^{\circ}$ Agr. Eduardo Montenegro, de Santa Tecla, El Salvador, e Sr. Raul Sahli, de Santa Ana, Fl Salvador.

(2) Há, em português, várias expressóes para significar "wilting point", entre as quais "água inativa" por nós empregada em trabalho anterior (4). Preferimos adotar definitivamente a expressăo inglêsa, por ser quase universalmente conhecida e não introduzir assim maiores complicaçōes na sinonímia portuģuêsa. 
disponível, seguimos para a América Central, em janeiro de 1950. Localizamo-nos no Instituto Interamericano de Ciências Agrícolas, em Turrialba, Costa Rica. Êsse Instituto, colaborando com o Govêrno de nosso Estado, nos deu hospedagem, pôs os seus laboratórios à nossa disposição e nos proporcionou uma viagem de estudos a El Salvador.

Turrialba situa-se na vertente do Atlântico, dista cêrca de sessenta quilômetros da Meseta Central e possui regime de chuvas muito abundantes, como se pode verificar abaixo:

MÊs

Janeiro

Fevereiro

Março

Abril

Maio

Junho

Julho

Agôsto

Setembro

Outubro.

Novembro

Dezembro

Ano

\section{Precipitação \\ $m m$}

148,8

85,3

80,2

$\mathbf{9 9 , 3}$

198,3

254,7

270,5

210,0

212,0

229,1

346,4

302,2

$2.436,8$
Frequência dias

16

10

11

12

9

16

22

18

17

18

18

18

185

$O$ fato de estar o Instituto Interamericano de Ciências Agrícolas em clima tão úmido, e distante da área que nos interessava, dificultou bastante o nosso trabalho. Interessava-nos trabalhar nos cafèzais da Meseta Central, que estão em clima sujeito a sêcas prolongadas. A falta de transporte fácil fêz com que o número de dados obtidos sôbre os solos de Costa Rica não fôsse tão elevado quanto desejávamos, embora suficiente para conclusões.

Interessava também aos nossos trabalhos estudar as condições r.a Nicarágua. Entretanto, isso não foi possível, dada a escassez do tempo. Preferimos demorar-nos mais em El Salvador e fazer, nesse país, maiux número de determinações de umidade do solo e coleta de amostras, a di. vidir o tempo disponível entre dois países, o que acarretaria estudos menos detalhados em cada um dêles, com maior perda de tempo.

\section{2 - OBSERVAÇÕES SÔBRE A CULTURA DO CAFł}

\section{1 - COSTA RICA}

A maior parte da cultura cafeeira de Costa Rica se acha na Meseta Central. Não seria necessário dizer que tôda ela é sombreada. As árvores de sombra empregadas são várias, predominando o ingàzeiro. Mesmo dêste, entretanto, há grande número de espécies. Existem em Costa Rica cêrca de 27 espécies de ingá. Na Meseta Central, os mais empregados no sombreamento são: Inga edulis Mart., I. golmanii Pittier e I. montealegrei. Usam também o I. spuria Humb. e Bonpl. Em Turrialba, os mais usados 
são I. marginata Willd, I. edrúlis Mart., I. pittierii Micheli e I. golmanii Pittier. Informaram-nos que o $I$. marginata tem raízes muito superficiais, o que dificulta a paléa ( $\left.{ }^{1}\right)$ e, por isso, está caindo em desuso. Além dêsses, e com menor frequência, encontram-se ainda nos cafèzais de Costa Rica : Inga leptoloba Sch., I. eriorhachis Harms., I. paterno Harms. (muito sujeito às moléstias) e I. tonduzii Donnell $\mathrm{Sm}$.

Os ingás que produzem frutos grandes são chamados de "guaba", e aos que produzem frutos pequenos chamam de "guajiniquil".

Principalmente na região de Turrialba, vêem-se ainda cafèzais sombreados por Erithrina glauca Willd. e Erithrina poeppigiana Bucare, também conhecida por "Poró", ambas introduzidas em Costa Rica, por Mariano Monte-Alegre, há cêrea de 50 anos. A primeira goza da fama de se prestar principalmente para lugares úmidos, por enxugar o terreno.

A Grevillea robusta e o Pisquim (Albizzia lebeek Benth.) são também empregados para sombreamento, em menor escala.

O espaçamento mais comum em Costa Rica é o de 2,5 metros para o cafeeiro e 10 metros para a árvore de sombra. Quando há bananeiras intercaladas, estas estão no espaçamento de 5 metros. Encontram-se, entretanto, frequentemente, espacamentos maiores e menores do que êste.

Em Costa Rica não usam a capina. Fazem geralmente a paléa, que consiste no revolvimento do solo com a pá. A profundidade atingida pela paléa é variável entre cinco e dez centímetros aproximadamente, e o seu custo anda ao redor de $\operatorname{Cr} \$ 260,00$ por hectare. Ao fazerem a paléa, amontoam a terra revolvida em redor da planta (aporca ou lomillo) ou no meio da rua (raspa). O mais geral é fazerem a raspa antes da colheita, para terem o chão limpo nessa ocasião. Dessa forma, os frutos caídos no chão, também aproveitados, são fàcilmente recolhidos.

Há uma certa tendência em substituir a paléa pela machetea, que consiste em cortar apenas o mato com o machete, uma espécie de facão. A razão dessa tendência é não só o custo menor dessa última operação, que fica em cêrca de Cr $\$ 90,00$ por hectare, como também evitar o dano que a paléa causa às raízes. A fazenda Atirro, na zona de Turrialba; iniciou, em 1950, o cultivo mecânico dos seus cafèzais, o que é feito com trator e arado de disco.

A poda é praticada em todos os cafèzais, e é do tipo em candelabro, já bem conhecido em cafeicultura como "poda de Costa Rica". É interessante o fato de os cafeeiros não produzirem econômicamente na América Central, senão até cêrca de quinze ou vinte anos de idade, segundo informações que lá obtivemos. A nosso ver, isso é devido principalmente à poda contínua a que submetem os cafeeiros, o que vai, aos poucos, mutilando aquelas plantas. No fim de alguns anos, o cafeeiro fica reduzido a uns poucos galhos muito compridos, com frutificação apenas nas extremidades. Nesse estado, os cafeeiros precisam ser eliminados e replantados. Devido a isso, não se vêem plantas de cinquenta ou mais anos, cono é comum encontrá-las em nossos cafèzais, e o serviço de replanta é bastante intenso.

(1) Paléa é o nome local para a prética agrícola de revolvimento do solo com a pá. 
A grande maioria de cafèzais de Costa Rica é da variedade typica (Coffea arabica L. var. typica Cramer) aí chamada "arabico". Há pouco bourbon - Coffea arabica L. var. bourbon (B. Rodr.) Choussy. Atualmente, está havendo uma grande procura do chamado "híbrido de Salvador". Visitamos um viveiro dêsse híbrido, que ocupava uma área de cêrca de doze hectares, encerrando cêrca de 350.000 plantas. Notamos grande variabilidade entre as plantas. Eram encontradas plantas da variedade typica e de bourbon.

Na Fazenda Tambor, nas proximidades da cidade de Alajuela, vimos um pequeno cafèzal formado por plantas do chamado "híbrido de Costa Rica", bastante produtivo e uniforme. $\overline{\mathbf{E}}$ aparentemente um bourbon ou um tipo muito próximo a êle. Êsse foi um dos cafèzais mais bonitos e produtivos que vimos em Costa Rica. Em uma área isolada, próxima de uma corrente de água, havia algumas plantas mais novas, sem sombreamento, exibindo grande vigor e uma produção ainda maior do que as sombreadas.

Visitamos ainda um pequeno cafèzal, que possuía plantas da variedade conhecida por San Ramon (Coffea arabica L. var. San Ramon Choussy), nas proximidades da cidade do mesmo nome. Dessa variedade, que apresenta grande variabilidade, o Instituto Agronômico de Campinas já possui exemplares. São muito produtivos em relação ao porte pequeno da planta, e sujeitos a intenso "die-back". Não vimos plantações dessa variedade em escala comercial.

A fazenda Trinidad, nas proximidades da cidade de Alajuela, irrigou em sulcos, grande parte de seu cafèzal, com objetivo experimental, tendo conseguido ótimo resultado, pois não sòmente o aspecto da lavoura melhorou muito como, também, o que é mais interessante, a produção aumentou consideràvelmente.

Também a fazenda Santa Helena, na mesma região, fêz a irrigação em sulcos em uma pequena parte de seus cafèzais, tendo-nos informado o agrônomo da região de que o aumento de produção foi de, aproximadamente, $100 \%$, o que, sem dúvida nenhuma, é um resultado extraordinàriamente animador.

\section{2 - EL SALVADOR}

Como podemos ver pelos dados pluviométricos de El Salvador (quadro 1), a estação sêca naquele país tem uma duração de cinco a seis meses, mais longa, portanto, do que a do Estado de São Paulo.

Viajando pelo país, no fim daquela estação, observamos os seus efeitos. Ao longe, quando a vegetação é rasteira, tudo é pardacento. Mesmo nas baixadas, raros são os minguados cursos de água que ainda correm. Quando êstes existem, vê-se ao longe a faixa sinuosa de vegetação verde, que os acompanha e denuncia. Essas faixas verdes acentuam ainda mais 0 aspecto triste das encostas crestadas. 
Os cafèzais, em sua maioria, apresentam-se murchos. Êste fato, que é muito comum em todos os lugares por onde passamos, é regra geral na zona leste do país, como nos foi dado observar em nossa viagem até a cidade Santiago de Maria.

O interessante é que os cafeeiros não derrubam as fôlhas. Estas murcham, mas permanecem prêsas às plantas e, quando as chuvas se iniciam, tornam-se de novo túrgidas.

Os melhores cafèzais de El Salvador estão nas regiões de San Salvador, Santa Tecla e Santa Ana, principais zonas cafeeiras do país.

O espaçamento do plantio do café em El Salvador é muito variável, mas, em geral, bem menor do que o usado em Costa Rica. Plantam, segundo informações do Sr. Felix Choussy, desde 800 até 2.000 cafeeiros por manzana $\left(7.000 \mathrm{~m}^{2}\right)$. Ao invés da poda pròpriamente dita, praticam a agobia, que consiste em dobrar a planta nova e prender a sua ponta ao chão. Dessa maneira, forçam a formação de brotos verticais, dos quais deixam crescer alguns.

Devido à grande falta de água na estação sêca, o despolpamento do café é uma operação muito cara em El Salvador. Isto porque tem que ser feito com água de chuva armazenada, durante a estação chuvosa, em grandes tanques de cimento ou ferro. Um tanque de ferro para 500.000 galões, ou sejam cêrca de 1.890 .000 litros, custa ao redor de 18.000 dólares. A água armazenada é geralmente também utilizada nos usos domésticos.

Os solos de El Salvador são, em geral, muito ricos em elementos minerais. A aplicação de matéria orgânica, entretanto, é necessária na maioria dos cafèzais. Em algumas fazendas, abrem valetas no cafèzal com um triplo objetivo: reter água das chuvas, combater a erosão, e para encherem-nas de matéria orgânica. Esta é fornecida pelas árvores de sombra e, frequentemente, aumentada artificialmente pela adição de composto, estrume, etc. Quando essas valetas se acham já cheias de detritos orgânicos, outras são abertas.

Todo o lixo da cidade de Santa Ana é utilizado na fabricação de composto, que é vendido, na própria fábrica, com o nome comercial de "Vitalumus", por um colon o quintal (Cr\$ 173,90 por tonelada). Aplicado no cafèzal, fica em un colon e vinte centavos por quintal (Cr\$208,70 por tonelada). A produção diária de "Vitalumus" é de $350-400$ quintais ou, em nossas unidades, 16 a 18,5 toneladas. Há planos para o aproveitamento também do lixo da capital, San Salvador, o que, sem dúvida, elevará a produção a mais do que o dôbro. E evidente em El Salvador o grande interêsse pelas práticas de estercadura dos cafèzais e defesa contra a erosão. Para esta última, empregam também o izote, plantado em linhas cortando as águas.

\section{3 - DADOS METEOROLOGICOS}

Os dados meteorológicos aqui analisados foram tirados dos trabalhos de Pittier (11), Sapper (12), e Lazo (10), e alguns gentilmente cedidos pelo Eng. ${ }^{\circ}$ Agr. ${ }^{\circ}$ Gregório Alfaro, do Instituto Interamericano de Ciências Agrícolas de Turrialba, Costa Rica. 
Quadro 1.-Médias mensais pluviométricas de dias chuvosos; da umidade relativa do e de Campinas, no

\begin{tabular}{|c|c|c|c|c|c|c|c|}
\hline \multirow{3}{*}{$\mathbf{M} \mathbf{E} \mathbf{S} \mathbf{S}$} & \multicolumn{5}{|c|}{ Precipitação pluviométrica } & \multicolumn{2}{|c|}{ Número de di } \\
\hline & \multicolumn{3}{|c|}{$\begin{array}{c}\text { Costa Rica } \\
\text { (Meseta Central) }\end{array}$} & \multirow{2}{*}{$\begin{array}{c}\text { El Sal- } \\
\text { vador } \\
\\
\text { (San } \\
\text { Sal- } \\
\text { vador) } \\
\text { (23 anos) }\end{array}$} & \multirow{2}{*}{$\begin{array}{l}\text { Brasil } \\
\text { (Cam- } \\
\text { pinas) } \\
\text { (60 } \\
\text { anos) }\end{array}$} & \multicolumn{2}{|c|}{$\begin{array}{c}\text { Costa Rica } \\
\text { (Meseta Central) }\end{array}$} \\
\hline & $\begin{array}{c}\text { San } \\
\text { José } \\
\text { (63 } \\
\text { anos) }\end{array}$ & $\begin{array}{c}\mathrm{Na}- \\
\text { ranjo } \\
(6 \\
\text { anos) }\end{array}$ & $\begin{array}{c}\text { Santa } \\
\text { Ana } \\
(8 \\
\text { anos) }\end{array}$ & & & $\begin{array}{c}\text { San } \\
\text { José } \\
\text { (34 } \\
\text { anos) }\end{array}$ & $\begin{array}{c}\text { Très } \\
\text { Rios } \\
(13 \\
\text { anos) }\end{array}$ \\
\hline & $m m$ & $m m$ & $m m$ & $m m$ & $m m$ & dias & $\operatorname{dics}$ \\
\hline Janeiro & 12,1 & 1,6 & 9,2 & 5,4 & 244,6 & 4 & 2 \\
\hline Fevereiro & 4,1 & 0,5 & 6,1 & 7,0 & 203,9 & 1 & 2 \\
\hline Março ..... & 15,1 & 2,6 & 24,7 & 11,2 & 149,3 & 3 & 2 \\
\hline Abril ...... & 49,4 & 22,6 & 52,5 & 51,9 & 60,4 & 7 & 5 \\
\hline Maio ...... & 215,0 & 277,4 & 224,4 & 197,1 & 50,7 & 19 & 14 \\
\hline Junho _... & 263,5 & 318,7 & 289,2 & 350,0 & 48,9 & 24 & 18 \\
\hline Julho _.... & 211,9 & 284,5 & 191,0 & 309,0 & 28,0 & 23 & 16 \\
\hline Agôsto & 236,6 & 435,0 & 152,0 & 306,4 & 34,3 & 24 & 18 \\
\hline Setembro... & 321.9 & 506,2 & 373,6 & 302,2 & 71,3 & 25 & 20 \\
\hline Outubro & 321,7 & 320,3 & 335,4 & 258,5 & 116,1 & 26 & 22 \\
\hline Novembro .. & 145,5 & 211,4 & 164,4 & 38,5 & 155,6 & 16 & 20 \\
\hline Dezembro & 37,2 & 91,2 & 13,1 & 13,7 & 228,2 & 9 & 6 \\
\hline Totais anuais $\ldots$ & $18: 34,0$ & 2472,0 & 1835,6 & 1842,2 & 1391,3 & 176 & 145 \\
\hline Médias gerais....- & -2 & . & $\ldots$ & 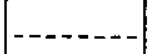 &.-- & & \\
\hline $\begin{array}{l}\text { Soma dos dados dos quatro meses } \\
\text { de menor precipitação }\end{array}$ & 68,5 & 27,3 & 53,1 & 37,3 & 161,9 & 17 & 11 \\
\hline $\begin{array}{l}\text { Média dos dados dos quatro } \\
\text { meses de menor precipitação }\end{array}$ & & & & & & & \\
\hline
\end{tabular}


ar, da temperatura do ar e da nebulosidade, em algumas localidades da América Central Estado de São Paulo

\begin{tabular}{|c|c|c|c|c|c|c|c|c|c|c|}
\hline \multicolumn{2}{|l|}{ chuvosos } & \multicolumn{3}{|c|}{ Umidade relativa do ar } & \multicolumn{3}{|c|}{ Temperatura } & \multicolumn{3}{|c|}{ Nebulosidade } \\
\hline $\begin{array}{l}\text { El Sal- } \\
\text { vador }\end{array}$ & Brasil & $\begin{array}{c}\text { Costa } \\
\text { Rica }\end{array}$ & $\begin{array}{c}\text { El Sal- } \\
\text { vador }\end{array}$ & Brasil & $\begin{array}{l}\text { Costa } \\
\text { Rica }\end{array}$ & $\begin{array}{l}\text { El Sal- } \\
\text { vador }\end{array}$ & Brasil & $\begin{array}{c}\text { Costa } \\
\text { Rica }\end{array}$ & $\begin{array}{l}\text { El Sal- } \\
\text { vador }\end{array}$ & Brasil \\
\hline $\begin{array}{c}\text { (San } \\
\text { Sal- } \\
\text { vador) } \\
(23 \\
\text { anos) } \\
\end{array}$ & $\begin{array}{c}\text { (Cam- } \\
\text { pinas) } \\
(53 \\
\text { anos) }\end{array}$ & $\begin{array}{c}\text { (San } \\
\text { José) } \\
(15 \\
\text { anos) } \\
\end{array}$ & $\begin{array}{c}\text { (San } \\
\text { Sal- } \\
\text { vador) } \\
(25 \\
\text { anos) }\end{array}$ & $\begin{array}{c}\text { (Cam- } \\
\text { pinas) } \\
(51 \\
\text { anos) }\end{array}$ & $\begin{array}{c}\text { (San } \\
\text { José) } \\
(15 \\
\text { anos) }\end{array}$ & $\begin{array}{c}\text { (San } \\
\text { Sal- } \\
\text { vador) } \\
(25 \\
\text { anos) }\end{array}$ & $\begin{array}{c}\text { (Cam- } \\
\text { pinas) } \\
(15 \\
\text { anos) }\end{array}$ & $\begin{array}{c}\text { (San } \\
\text { José) } \\
(11 \\
\text { anos) } \\
\end{array}$ & $\begin{array}{c}\text { (San } \\
\text { Sal- } \\
\text { vador) } \\
(14 \\
\text { anos) }\end{array}$ & $\begin{array}{c}\text { (Cam- } \\
\text { pinas) } \\
(15 \\
\text { anos) }\end{array}$ \\
\hline dias & dias & $\%$ & $\%$ & $\%$ & ${ }^{\circ} \mathrm{C}$ & ${ }^{\circ} \mathrm{C}$ & ${ }^{\circ} \mathrm{C}$ & & & \\
\hline 1 & 17 & 76 & 69 & 78 & 18,8 & 22,3 & 22,5 & 4,9 & 2,4 & 6,9 \\
\hline 1 & 14 & 72 & 68 & 79 & 19,4 & 22,8 & 22,6 & 4,5 & 3,1 & 6,8 \\
\hline 1 & 12 & 72 & 69 & 78 & 19,8 & 23,7 & 22,2 & 4,8 & 4,1 & 5,5 \\
\hline 4 & 6 & 73 & 70 & 75 & 20,4 & 24,3 & 20,4 & 6,0 & 5,6 & 4,6 \\
\hline 13 & 5 & 81 & 79 & 75 & 20,5 & 24,3 & 18,0 & 7,6 & 7,0 & 3,6 \\
\hline 20 & $\mathbf{5}$ & 85 & 82 & 75 & 20,1 & 23,3 & 16,7 & 7,9 & 7,5 & 3,7 \\
\hline 19 & 3 & 84 & 80 & 71 & 19,8 & 23,6 & 16,4 & 8,0 & 7,3 & 3,4 \\
\hline 19 & 4 & 81 & 81 & 67 & 19,7 & 23,6 & 17,9 & 7,5 & 7,3 & 3,1 \\
\hline 19 & 7 & 85 & 84 & 68 & 19,8 & 23,1 & 19,2 & 7,7 & 7,6 & 5,9 \\
\hline 16 & 8 & 86 & 82 & 70 & 19.6 & 23,0 & 20,4 & 8,0 & 6,4 & 5,9 \\
\hline 4 & 11 & 83 & 72 & 71 & 19,4 & 22,5 & 21,3 & 6,9 & 4,6 & 5,8 \\
\hline 2 & 15 & 79 & 72 & 76 & 18,8 & 22,4 & 22,1 & 5,7 & 2,4 & 6,8 \\
\hline 119 & 108 & - - - & ------ & - & --- & $-\ldots-\ldots$ & 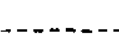 & -----1 & $-----1 .-$ & - - - - - \\
\hline & --- & 80 & 75 & 73 & 19,7 & 23,2 & 20,0 & 6,6 & 5,4 & 5,2 \\
\hline 5 & 17 & & & & & & & 19,9 & 12,0 & 13,8 \\
\hline & $-\ldots$ & 75 & 69 & 72 & 19,2 & 22,8 & 17,2 & ----- & - & - \\
\hline
\end{tabular}




\section{1 - QUEDA PLUVIOMÉTRICA}

A simples vista dos dados de queda pluviométrica de El Salvador e da Meseta Central de Costa Rica, vê-se que o período de sêca dessas duas regiões é mais prolongado do que o que ocorre no planalto paulista. No quadro 1, a queda pluviométrica mensal da Meseta Central de Costa Rica, que é a região verdadeiramente cafeeira do país, é representada por San José (capital), Naranjo e Santa Ana. Ainda no mesmo quadro se acham os dados relativos a San Salvador, na República de El Salvador, e Campinas. A fim de compararmos os períodos de sêca, fizemos a soma da queda pluviométrica dos quatro meses mais secos de cada um dos lugares estudados. Por ela se vê, que, de fato, a sêca na Meseta Central de Costa Rica e em San Salvador é mais rigorosa do que em Campinas, considerando-se a queda pluviométrica. A figura 1 mostra os totais pluviométricos anuais de San José com as médias aritmética e progressiva desde 1865 até 1949, com interrupção de seis anos entre 1880 e 1887, dos quais faltam os dados.

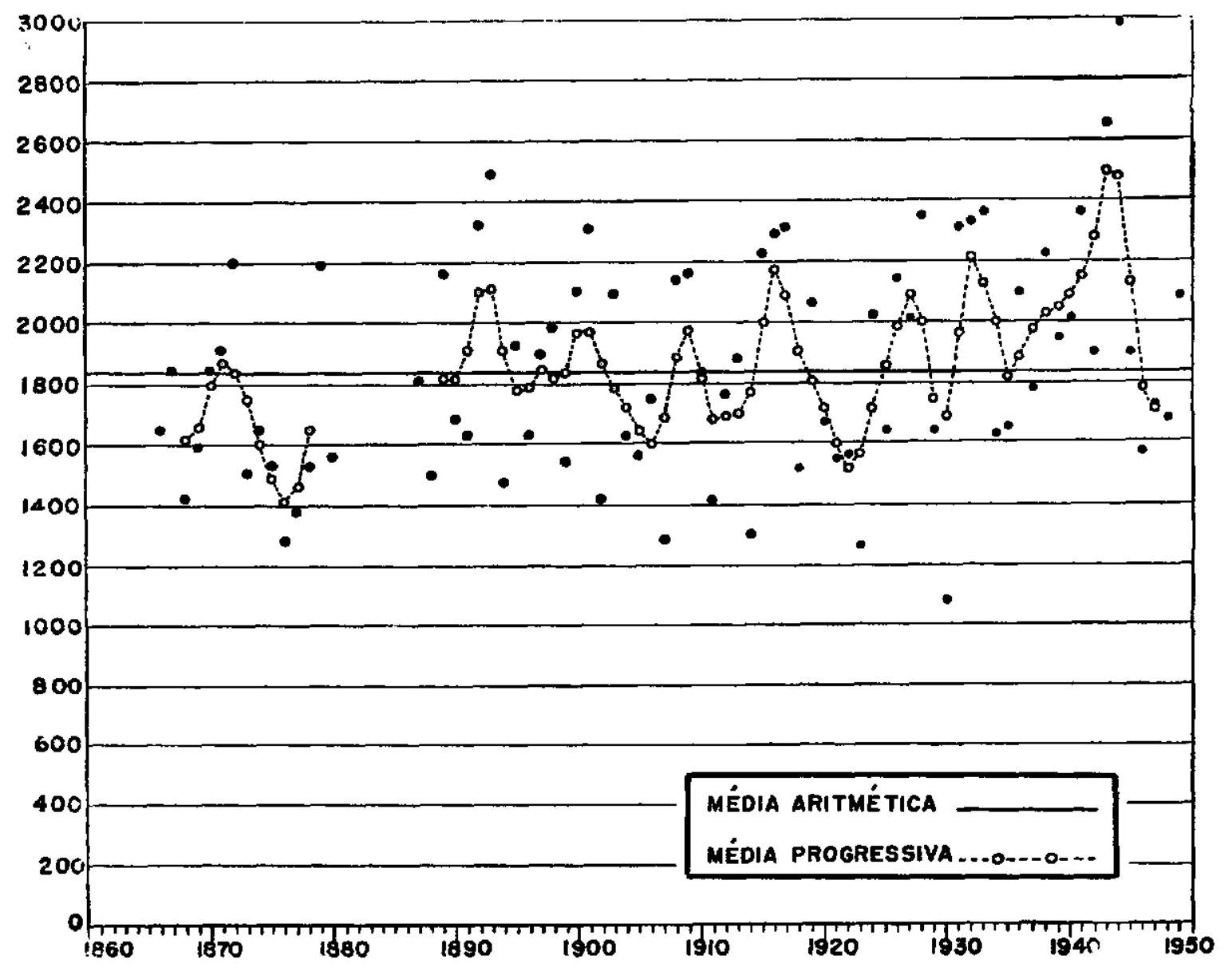

Figura 1.-Totais pluviométricos anuais de San José, Costa Rica.

\section{2 - FREQUENCIA}

Os dados de frequência, ou seja número de dias chuvosos, acham-se no quadro 1. Vê-se que também a frequência de chuvas nas regiões cafeeiras estudadas em Costa Rica e em EI Salvador são inferiores à de 
Campinas, sendo notável a diferença entre esta última cidade, com dezessete dias de chuva, em média, nos quatro meses de menor queda pluviométrica do ano, e em San Salvador, com a média de apenas cineo dias chuvosos no mesmo período. Assim, pois, também o estudo da frequência mostra ser o período sêco de El Salvador mais severo do que o de São Paulo, e, o da Meseta Central de Costa Rica, mais ou menos equivalente ao nosso.

\section{3 - UMTDADE RELATIVA DO AR}

As diferenças nas médias dos dados de umidade relativas, que se acham no quadro 1, são pequenas e não explicariam nenhuma diferença no comportamento de cafèzais à sombra. Nota-se que a umidade relativa média de ar em San Salvador é pràticamente a mesma que em Campinas (5). A de San José, em Costa Rica, é um pouco superior às das duas primeiras consideradas.

\section{4 - TEMPERATURA}

No quadro 1 vê-se ainda que as médias anuais da temperatura de San José, em Costa Rica, San Salvador, em El Salvador, e Campinas são bastante semelhantes. Examinando agora as médias dos quatro meses mais secos, vemos que o período de sêca em Campinas é mais frio do que o das outras duas localidades em estudo, sendo de $5,6^{\circ} \mathrm{C}$, a diferença entre Campinas e San Salvador.

Considerando-se, pois, sòmente a temperatura, as plantas em Campinas deveriam consumir menor quantidade de água do que as de San José e San Salvador.

\section{5 - NEBULOSIDADE}

Para avaliação da nebulosidade, considera-se a abóbada celeste inteiramente livre de nuvens, como 0 , e inteiramente encoberta, como 10. A avaliação é feita visualmente, tomando-se por base êsses dois limites. Pelo quadro 1 vê-se que as nebulosidades em San José, San Salvador e Campinas são bastante semelhantes, sendo as de San Salvador e Campinas pràticamente idênticas.

\section{4 - ESTUdOS SÔBRE A ÁGUA DO SOLO}

\section{1 - METTODOS}

\subsection{1 - COLETA DE AMOSTRAS}

As amostras foram coletadas pelo mesmo método empregado nos trabalhos realizados no Estado de São Paulo. Abriu-se um buraco com o auxílio de uma cavadeira e retirou-se terra das profundidades de $0,5,1,0$ e, frequentemente, também de 1,5 metros. As amostras foram imediatamente colocadas em frascos de vidro, que, por sua vez, foram hermèticamente fechados por uma tampa rosqueada sôbre uma junta de borracha e, assim, levadas para o laboratório. 


\subsection{2 - DETERMINACXO DA UMIDADE}

Antes de serem abertos os fráscos contendo as amostras, foram êles bem agitados, para no caso de haver gotículas de água condensadas nas paredes internas, o que frequentemente acontece, serem elas reabsorvidas pela terra. Todo o conteúdo do frasco foi usado na determinação da percentagem de umidade, que foi feita a $103-105^{\circ} \mathrm{C}$ e expressa em relação ao pêso inicial úmido.

\subsection{3. - DETERMINAgaO DO "WILTING POINT"}

As determinações do "wilting point" foram feitas pelo método direto, de Briggs e Shantz (1), com pequenas modificações. Após passar por peneira de malhas de três milímetros, a terra foi colocada em frascos de vidro de bôca larga de capacidade aproximada de $150 \mathrm{cc}$, que serviram de vasos. Em cada frasco plantou-se uma semente de feijão, Phaseolus vulgaris L., variedade conhecida em Costa Rica por Chimbolo, que se prestou bem para planta indicadora. A rega inicial da terra no interior dos frascos foi feita com solução nutritiva de Hoagland diluída a 1:1, para assegurar bom desenvolvimento às plantinhas, pois as amostras tomadas a 1,0 e 1,5 metros de profundidade geralmente não têm quantidade de elementos absorvíveis suficiente para o desenvolvimento normal das plantas.

Quando as plantinhas apresentavam o primeiro par de fôlhas verdadeiras bem desenvolvido, os frascos foram fechados hermèticamente com uma tampa de papelão parafinado, tendo uma fenda para passagem do caule ao se fechar. Essa ranhura foi depois fechada com fita isolante, com o que também se fixava todo o bordo da tampa à bôca do frasco. Os interstícios em tôrno do caule foram fechados com mástique de breu e cêra. Isto feito, as plantas foram deixadas murchar ao abrigo do sol, a fim de que o murchamento se desse lentamente. Se a transpiração fôr muito intensa, a planta pode murchar por excesso da transpiração sôbre a absorção de água, apesar de existir ainda no solo água absorvível. Logo que as plantas exibiam sintomas de murchidão, eram levadas para uma câmara úmida, a fim de que, diminuindo bastante a transpiração, as fôlhas readquirissem a turgescência. Túrgidas, eram levadas novamente ao ambiente anterior para transpirarem mais, e, assim, sucessivamente, até não mais recobrarem a turgescência na câmara úmida ou murcharem dentro de poucos minutos apenas após serem dela retiradas. Assim, atingido o "wilting point" do solo, os frascos eram abertos, a umidade do solo determinada em estufa a $103^{\circ} \mathrm{C}$, e calculada sôbre o pêso úmido inicial.

\subsection{4 - DETERMINACAO DO “MOISTURE EQUIVALENT"}

Esta constante do solo foi determinada pelo método clássico, da centrifugação, para o que utilizamos uma centrífuga especial "Internationa] Centrifuge, Model ME", construída pela "International Equipment Co., Boston, Mass., U.S.A." 


\section{5 - RESULTADOS}

\section{1 - COSTA RICA}

Como já dissemos na introdução, em Costa Rica trabalhamos no planalto central do país, onde está localizada a grande maioria da cultura cafeeira e onde o clima se assemelha ao de São Paulo, principalmente no que concerne à pluviometria. As amostras de solo foram retiradas no período de 21 a 28 de fevereiro de 1950 , portanto, no período mais sêco do ano naquela região.

As determinações de "wilting point" e "moisture equivalent" foram feitas nas mesmas amostras de terra, e com três repetições. O quadro 2 mostra os resultados parciais e as médias. É digna de nota a pequena variação registada entre as repetições das mesmas amostras, o que evidencia a eficácia do método e da técnica empregada.

Quadro 2.- "Wilting point" e "Moisture equivalent" do solo nos locais onde foi determinada a água disponível em Costa Rica

\begin{tabular}{|c|c|c|c|c|c|c|c|}
\hline \multicolumn{3}{|c|}{ Amostras de solo } & \multirow[b]{2}{*}{$\begin{array}{l}\text { "Wilting } \\
\text { point" }\end{array}$} & \multirow[b]{2}{*}{ Média } & \multirow{2}{*}{$\begin{array}{l}\text { "Mois- } \\
\text { ture } \\
\text { equiva- } \\
\text { lent" }\end{array}$} & \multirow[b]{2}{*}{ Média } & \multirow{2}{*}{$\frac{\text { M.E. (1) }}{\text { W.P. }}$} \\
\hline Procedência & $\begin{array}{l}\text { Profun- } \\
\text { didade } \\
\text { em } \\
\text { metros }\end{array}$ & Número & & & & & \\
\hline & & & $\%$ & $\%$ & $\%$ & $\%$ & \\
\hline Fazenda Trinidad (local n..$^{\circ}$ ) & $0,5-1,8$ & $\left\{\begin{array}{l}1 \ldots \\
1 \mathrm{a}- \\
1 \mathrm{~b}-\end{array}\right.$ & $\begin{array}{l}22,5 \\
22,0 \\
22,2\end{array}$ & 22,2 & $\begin{array}{l}28,3 \\
28,3 \\
28,2\end{array}$ & 28,3 & 1,27 \\
\hline Fazenda Trinidad (local n.. 2) & $0,5-1,0$ & $\left\{\begin{array}{l}2-\ldots \\
2 a-5 \\
2 b-\end{array}\right.$ & $\begin{array}{l}21,9 \\
21,9 \\
21,3\end{array}$ & 21,7 & $\begin{array}{l}31,7 \\
31,9 \\
31,6\end{array}$ & \} 31,7 & 1,46 \\
\hline Fazenda Trinidad (local n.o 2) & $1,0-1,2$ & $\left\{\begin{array}{l}3-- \\
3 \mathrm{a}- \\
3 \mathrm{~b}-\end{array}\right.$ & $\begin{array}{l}25,5 \\
25,6 \\
25,5\end{array}$ & \}$_{25,5}$ & $\begin{array}{l}31,6 \\
31,3 \\
31,3\end{array}$ & \} 31,4 & 1,23 \\
\hline Sítio Tambor ... & $0,5-1,5$ & $\left\{\begin{array}{l}4-\ldots \\
4 a- \\
4 b-\end{array}\right.$ & $\begin{array}{l}27,6 \\
28,0 \\
28,3\end{array}$ & 27,9 & $\begin{array}{l}33,8 \\
33,8 \\
33,4\end{array}$ & \} 33,7 & 1,21 \\
\hline Sítio Santa Helena & $0,5-1,0$ & $\left\{\begin{array}{l}5-- \\
5 \mathrm{a}- \\
5 \mathrm{~b}-\end{array}\right.$ & $\begin{array}{l}23,7 \\
23,8 \\
23,3\end{array}$ & \} 23,6 & $\begin{array}{l}31,8 \\
31,5 \\
31,4\end{array}$ & \} 31,6 & 1,34 \\
\hline Sítio "La Margarita" -. & $0,5-1,1$ & $\left\{\begin{array}{l}6 \ldots \\
6 \mathrm{a} \ldots \\
6 \mathrm{~b}\end{array}\right.$ & $\begin{array}{l}23,3 \\
23,4 \\
23,5\end{array}$ & 23,4 & $\begin{array}{l}28,8 \\
28,9 \\
28,7\end{array}$ & \} 28,8 & 1,23 \\
\hline
\end{tabular}

(1) M.E. = "moisture equivalent" ; W.P. = "wilting point".

No quadro 3 estão os dados da umidade do solo, "wilting point", e água disponível dos solos estudados em Costa Rica.

As amostras de números 1 a 3 , da fazenda Trinidad (local n. ${ }^{\circ} 1$ ), foram retiradas na parte mais baixa do cafèzal, que apresentava bom aspecto. $\mathrm{O}$ solo é bastante argiloso e compacto. Havia nesse local uma. 
cova de 0,8 $\mathrm{m}$ de profundidade, feita por alunos da Escola de Agronomia, os quais, alguns dias antes, de lá haviam retirado terra para estudo. Aumentando a profundidade dessa cova, retiramos as amostras acima referidas.

As amostras de número 4 a 7 foram retiradas na mesma fazenda, na parte mais alta do cafèzal (local n. ${ }^{\circ} 2$ ). 0 solo era bastante argiloso, porém menos compacto do que o do local número 1 . Notava-se grande abundância de radicelas até o fundo da valeta aberta.

O cafèzal do sítio Tambor é pequeno, porém, dos mais bonitos e produtivos de Costa Rica. Situa-se na parte mais alta de um morro, encostado à raiz das fraldas do vulcão Poás. O sombreamento é feito com ingàzeiro e o solo relativamente fôfo, fácil de ser cavado, apesar de aparentemente bastante argiloso. $O$ perfil mostrava-se muito uniforme até a profundidade máxima estudada. Distante cêrca de 50 metros do cafèzal, havia um poço com 17 metros de profundidade, o qual, entretanto, não havia alcançado água, o que mostra que o lençol freático, nesse local, se acha a grande profundidade.

Quadro 3.-Āgua disponivel nos cafèzais estudados em Costa Rica

\begin{tabular}{|c|c|c|c|c|c|}
\hline \multicolumn{3}{|c|}{ A mostras de solo } & \multirow{2}{*}{$\begin{array}{l}\text { Umidade } \\
\text { encon- } \\
\text { trada }\end{array}$} & \multirow{2}{*}{$\begin{array}{l}\text { "Wilting } \\
\text { point" }\end{array}$} & \multirow{2}{*}{$\begin{array}{c}\text { Água dis- } \\
\text { ponível }\end{array}$} \\
\hline Procedência & $\begin{array}{l}\text { Profundi- } \\
\text { dade em } \\
\text { metros }\end{array}$ & Número & & & \\
\hline Fazenda Trinidad (local n.0 1) -.- & $\left\{\begin{array}{l}1,5_{\ldots} \ldots \\
1,5 \ldots \\
1,8_{\ldots}\end{array}\right.$ & $\begin{array}{l}1 \\
2 \\
3 \\
3\end{array}$ & $\begin{array}{l}\% \\
26,8 \\
26,9 \\
25,7\end{array}$ & $\begin{array}{l}\% \\
22,2 \\
22,2 \\
22,2\end{array}$ & $\begin{array}{ll}\% & \\
& 4,6 \\
& 4,7 \\
& 3,5\end{array}$ \\
\hline Fazenda Trinidad (local n.॰ 2) & $\left\{\begin{array}{l}0,5 \ldots \\
0,7 \ldots \\
1,0 \ldots \\
1,2 \ldots\end{array}\right.$ & $\begin{array}{l}4-1 . \\
5 \\
6 \\
7 \\
7\end{array}$ & $\begin{array}{l}25,8 \\
29,4 \\
27,9 \\
31,5\end{array}$ & $\begin{array}{l}21,7 \\
25,5 \\
25,5 \\
25,5\end{array}$ & $\begin{array}{l}4,1 \\
3,9 \\
2,4 \\
6,0\end{array}$ \\
\hline Sítio Tambor ...................... & $\left\{\begin{array}{l}0,5=- \\
0,7- \\
1,0=- \\
1,5 \ldots\end{array}\right.$ & $\begin{array}{r}8 \\
9 \\
10 \\
11\end{array}$ & $\begin{array}{l}36,7 \\
33,6 \\
39,5 \\
36,5\end{array}$ & $\begin{array}{l}27,9 \\
27,9 \\
27,9 \\
27,9\end{array}$ & $\begin{array}{r}8,8 \\
5,7 \\
11,6 \\
8,6\end{array}$ \\
\hline Sítio Santa Helena.... & $\left\{\begin{array}{l}0,5_{-} \\
1,0_{-}\end{array}\right.$ & $12 \ldots-\ldots$ & $\begin{array}{l}28,9 \\
31,8\end{array}$ & $\begin{array}{l}23,6 \\
23,6\end{array}$ & $\begin{array}{l}5,3 \\
8,2\end{array}$ \\
\hline Sítio "La Margarita"--. & $\left\{\begin{array}{l}0,5 \\
0,8 \ldots \\
1,0 \ldots \\
1,1 \ldots\end{array}\right.$ & $\begin{array}{l}14 \ldots \\
15 \\
16 \\
17\end{array}$ & $\begin{array}{l}25,9 \\
28,0 \\
30,9 \\
31,1\end{array}$ & $\begin{array}{l}23,4 \\
23,4 \\
23,4 \\
23,4\end{array}$ & $\begin{array}{l}2,5 \\
4,6 \\
7,5 \\
7,7\end{array}$ \\
\hline
\end{tabular}

No sítio Santa Helena, o cafèzal é velho e muito ruim, por deficiência de tratos, principalmente defesa contra a erosão e.adubação. $O$ sombreamento é feito com "Madre del Cacao" e eritrina. O cafèzal do sítio "La Margarita" situa-se em lugar alto, aparentemente sêco, sem nenhuma água nos arredores. Os cafeeiros são bem enfolhados; o sombreamento, feito com eritrina, bastante denso. $O$ solo é bastante fôfo até cêrca de $0,4 \mathrm{~m}$, tornando-se, daí para baixo, cada vez mais firme até que, a um metro de profundidade, já se mostrava bastante compacto. 


\section{2 - EI, SATVADOR}

As duas principais zonas cafeeiras de El Salvador são as de San Salvador e Santa Ana. Por essa razão, escolhemos essas duas regiões para a execuȩão dos nossos trabalhos de determinação de água disponível no solo. A coleta de amostras foi feita no período compreendido entre 5 a 20 de abril de 1950. A última chuva apreciável em Santa Tecla, na região de El Salvador, anterior ao período em que as amostras foram coletadas,

Quadro 4.--"Wilting point" e "Mristure equivalent". em diferentes amostras de solo dos locais onde foi determinada a água disponível en El Salvador

\begin{tabular}{|c|c|c|c|c|c|c|}
\hline A mostras & & & & "Mois- & & T \\
\hline Procedência & $\begin{array}{l}\text { Profundi- } \\
\text { dade em } \\
\text { metros }\end{array}$ & "Wilting & Média & $\begin{array}{l}\text { ture } \\
\text { equiva- } \\
\text { lent" }\end{array}$ & Média & $\frac{\text { M. E. (1) }}{\text { W. P. }}$ \\
\hline & & $\%$ & $\%$ & $\%$ & $\%$ & \\
\hline $\begin{array}{c}\text { Centro Nacional de Agronomia - local } \\
\text { n. } 1 \text { - }\end{array}$ & $0,5-1,5$ & $\begin{array}{r}11,1 \\
9.7 \\
10,6\end{array}$ & 10,5 & 21,3 & 21,3 & 2,03 \\
\hline $\begin{array}{l}\text { Centro Nacional de Agronomia - local } \\
\text { n.o } 2 \text { - }\end{array}$ & $0,5-1,5$ & $\begin{array}{r}7,7 \\
-7,8\end{array}$ & 7,7 & $\begin{array}{l}16,8 \\
16,4\end{array}$ & 16,6 & 2,15 \\
\hline Sítio "Perceveranza" — Santa Ana -- & $0,5-1,5$ & $\begin{array}{l}23,5 \\
22,0\end{array}$ & 22,7 & $\begin{array}{l}34,8 \\
35,3\end{array}$ & 35,5 & 1,56 \\
\hline $\begin{array}{l}\text { Sítio Montserrat - Santa Ana - local } \\
\text { n.0 } 1\end{array}$ & $0,5-1,5$ & $\begin{array}{l}23,5 \\
23,7 \\
23,7\end{array}$ & 23,6 & $\begin{array}{l}32,3 \\
32,7\end{array}$ & 32,5 & 1,38 \\
\hline $\begin{array}{c}\text { Sítio Montserrat - Santa Ana - loca } \\
n 0^{0} 2 \text { - }\end{array}$ & $0,5-1,5$ & $\begin{array}{l}19,5 \\
18,7\end{array}$ & 19,1 & $\begin{array}{l}27,5 \\
27,6\end{array}$ & 27,5 & 1,44 \\
\hline Sítio "El Campanario" - Santa Ana .. & $0,5-1,5$ & $\left\{\begin{array}{l}27,5 \\
27,6 \\
25,4\end{array}\right.$ & 26,8 & $\begin{array}{l}36,2 \\
36,9\end{array}$ & 36,5 & 1,36 \\
\hline Sítio Atlântida - Santa Ana ......... & $0,5-1,5$ & $\left\{\begin{array}{l}20,1 \\
21,5 \\
20,5\end{array}\right.$ & 20,7 & $\begin{array}{l}28,5 \\
28,7\end{array}$ & 28,6 & 1,38 \\
\hline Sítio La Flora - Santa Ana ..... & $0,5-1,5$ & $\left\{\begin{array}{l}\cdots \cdots \\
\cdots\end{array}\right.$ & 21,2 & $\begin{array}{l}32,2 \\
33,1\end{array}$ & 32,7 & 1,54 \\
\hline Sítio Florência - Santa Tecla & $0,5-1,5$ & $\left\{\begin{array}{l}10,6 \\
10,9 \\
10,8\end{array}\right.$ & 10,8 & $\begin{array}{l}17,3 \\
17,2\end{array}$ & \} & 1,59 \\
\hline Sítio El Olvido - Santa Tecla & $0,5-1,5$ & $\begin{array}{l}8,6 \\
8,9\end{array}$ & \} & $\begin{array}{l}17,7 \\
17,3\end{array}$ & \} 17,5 & 2,01 \\
\hline
\end{tabular}

(1) M.E. = "moisture equivalent"; W.P. = "wilting point".

foi registada em 12 de novembro de 1949, tendo atingido 30,5 milímetros. Depois dessa chuva, houve apenas chuvisqueiros, a saber : em 6 de janeiro de $1951-0,5 \mathrm{~mm}$; è̈ 12 de janeiro $-5 \mathrm{~mm}$; em 7 de marẹo $-2,3 \mathrm{~mm}$; em 16 de março de 1951 - 1,5 mm. Em 11 e 12 de abril de 1951, já dentro do período de coleta de amostras, choveu, respectivamente, 6,3 e 11,8 milímetros. Êsses chuvisqueiros não chegaram, certamente, a influenciar a umidade do solo, senão nos primeiros centímetros superficiais; 
uma vez que as amostras foram coletadas a uma profundidade de $0,5 \mathrm{~m}$ e mais, os resultados não foram por êles influenciados. As amostras foram, portanto, coletadas após, pràticamente, cinco meses de sêca.

Na região de Santa Ana, houve algumas pequenas precipitações, no mês de janeiro, anteriores à retirada de amostras, a saber : 5 de janeiro de $1950-6 \mathrm{~mm} ; 6$ de janeiro $-15 \mathrm{~mm} ; 12$ de janeiro $-2 \mathrm{~mm} ; 25 \mathrm{de}$ janeiro $-9 \mathrm{~mm}$ e 11 de abril de $1950-21 \mathrm{~mm}$. Vemos que, em janeiro, o total de chuvas foi de $32 \mathrm{~mm}$, e que depois sòmente choveu $21 \mathrm{~mm} \mathrm{em}$ abril. Essas pequenas precipitações, certamente, não tiveram influência na umidade do solo a uma profundidade de $0,5 \mathrm{~m}$.

No quadro 4 vemos os resultados parciais e as médias das determinações de "wilting point" e "moisture equivalent", em El Salvador.

Os resultados das determinações de umidade, "wilting point" e água disponível nos solos dos cafèzais de El Salvador, acham-se no quadro 5, na sequência em que foram obtidos.

QUADro 5.-Cálculo de água disponível nos cafèzais estudados de El Salvador

\begin{tabular}{|c|c|c|c|c|c|}
\hline A most $\mathbf{m}$ a s & o 10 & & $\mathrm{Um}$ & & \\
\hline Procedência & $\begin{array}{l}\text { Profundi- } \\
\text { dade em } \\
\text { metros }\end{array}$ & $\begin{array}{l}\text { Numero } \\
\text { das } \\
\text { amostras }\end{array}$ & $\begin{array}{l}\text { encon- } \\
\text { trada }\end{array}$ & point" & ponivel \\
\hline & & & $\%$ & $\%$ & $\%$ \\
\hline $\begin{array}{l}\text { Centro Nacional de Agronomia - Santa Te- } \\
\text { cla (local n.o 1) }\end{array}$ & $\left\{\begin{array}{l}0,5 \\
1,0 \\
1,5\end{array}\right.$ & 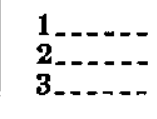 & $\begin{array}{l}17,8 \\
22,5 \\
19,7\end{array}$ & $\begin{array}{l}10,5 \\
10,5 \\
10,5\end{array}$ & $\begin{array}{r}7,3 \\
12,0 \\
9,2\end{array}$ \\
\hline $\begin{array}{l}\text { Centro Nacional de Agronomia - Santa Tecla } \\
\text { (local n.0 2) }\end{array}$ & $\left\{\begin{array}{l}0,5 \\
1,0 \\
1,5\end{array}\right.$ & 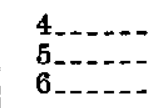 & $\begin{array}{r}8,7 \\
17,6 \\
18,9\end{array}$ & $\begin{array}{l}\mathbf{7 , 7} \\
\mathbf{7 , 7} \\
\mathbf{7 , 7}\end{array}$ & $\begin{array}{r}1,0 \\
9,9 \\
11,2\end{array}$ \\
\hline Sítio "Perceveranza" — Santa Ana & $\left\{\begin{array}{l}0,5_{--} \\
1,0_{--} \\
1,5_{--}\end{array}\right.$ & 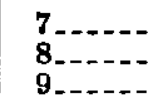 & $\begin{array}{l}23,5 \\
26,4 \\
34,2\end{array}$ & $\begin{array}{l}22,7 \\
22,7 \\
22,7\end{array}$ & $\begin{array}{r}\mathbf{0 , 8} \\
\mathbf{3 , 7} \\
\mathbf{1 1 , 5}\end{array}$ \\
\hline Sítio Montserrat - Los Naranjos (local n.o 1) & $\left\{\begin{array}{l}0,5 \ldots \\
1,0 \ldots \\
1,5 \ldots\end{array}\right.$ & 10 & $\begin{array}{l}28,9 \\
36,1 \\
32,1\end{array}$ & $\begin{array}{l}23,6 \\
23,6 \\
23,6\end{array}$ & $\begin{array}{r}5,3 \\
12,5 \\
8,5\end{array}$ \\
\hline Sítio Montserrat - Los Naranjos (local n.* 2) & $\left\{\begin{array}{l}0,5 \\
1,0-- \\
1,5--\end{array}\right.$ & $\begin{array}{l}13 \ldots \ldots \\
14 \ldots \ldots \\
15\end{array}$ & $\begin{array}{l}22,5 \\
36,0 \\
32,1\end{array}$ & $\begin{array}{l}19,1 \\
19,1 \\
19,1\end{array}$ & $\begin{array}{r}3,4 \\
16,9 \\
13,0\end{array}$ \\
\hline Śfio “El Campanario" — Santa Ana & $\left\{\begin{array}{l}0,5_{-} \\
1,0 \ldots \\
1,5_{-}\end{array}\right.$ & $\begin{array}{l}16 \\
17 \ldots \ldots \\
18 \ldots\end{array}$ & $\begin{array}{l}29,3 \\
34,2 \\
38,8\end{array}$ & $\begin{array}{l}26,8 \\
26,8 \\
26,8\end{array}$ & $\begin{array}{r}2,5 \\
7,4 \\
12,0\end{array}$ \\
\hline Sítio Atlântida $\longrightarrow$ Santa Ana & $\left\{\begin{array}{l}0,5_{-} \\
1,0_{-} \\
1,5_{-}\end{array}\right.$ & $\begin{array}{l}19 \ldots \ldots \\
20 \ldots \\
21 \ldots \ldots\end{array}$ & $\begin{array}{l}26,6 \\
33,1 \\
33,5\end{array}$ & $\begin{array}{l}20,7 \\
20,7 \\
20,7\end{array}$ & $\begin{array}{r}5,9 \\
12,4 \\
12,8\end{array}$ \\
\hline Sítio Florência - Santa Tecla - & $\left\{\begin{array}{l}0,5_{-} \\
1,0_{\ldots} \\
1,5_{\ldots}\end{array}\right.$ & $\begin{array}{l}22 \\
23 \ldots \ldots \\
24 \ldots \ldots\end{array}$ & $\begin{array}{l}10,1 \\
18,7 \\
27,0\end{array}$ & $\begin{array}{l}10,8 \\
10,8 \\
10,8\end{array}$ & $\begin{array}{r}0 \\
7,9 \\
16,2\end{array}$ \\
\hline Sítio El Olvido - Santa Tecla _. & $\left\{\begin{array}{l}0,5 \\
1,0- \\
1,5-\end{array}\right.$ & $\begin{array}{l}25 \ldots \\
26 \ldots \\
27 \ldots\end{array}$ & $\begin{array}{l}13,3 \\
20,6 \\
23,3\end{array}$ & $\begin{array}{l}\mathbf{8 , 7} \\
\mathbf{8 , 7} \\
\mathbf{8 , 7}\end{array}$ & $\begin{array}{r}4,6 \\
11,9 \\
14,6\end{array}$ \\
\hline & & & & & \\
\hline
\end{tabular}


O cafèzal do Centro Nacional de Agronomia, em Santa Tecla, tinha bom aspecto no local $n .^{\circ} 1$, e apresentava-se bem enfolhado. $O$ solo é bastante rico em cinza vulcânica e as raízes o exploravam com abundantes radicelas até a profundidade máxima estudada.

Ainda no cafèzal do Centro Nacional de Agronomia, em Santa Tecla, havia uma parte mais baixa, onde os cafeeiros se apresentavam com feio aspecto, bastante despidos de fôlhas. $O$ solo era semelhante ao anterior, porém de coloração mais escura. Nesse local (local $n .^{\circ} 2$ ), tiramos as amostras para determinação de água disponível, as quais receberam os números de 4 a 6.

O solo do cafèzal do sítio Perceveranza é aparentemente rico e fôfo. 0 sombreamento é feito com ingàzeiros e "Madre del Cacao".

$O$ melhor cafèzal que vimos na América Central foi o do sítio "Montserrat", em "Los Naranjos", El Salvador. O solo era riquíssimo, formado por aluvião recente. São dêsse cafèzal as amostras de números 10 a 15, tomadas em dois lugares diferentes.

No sítio "El Campanario", o cafèzal era bom e sombreado com ingàzeiros e "Madre del Cacao". Dêle foram retiradas as amostras de números 16 a 18.

As amostras de números 19 a 21 foram tomadas no cafèzal do sítio "Atlântida", onde o sombreamento era feito com "Madre del Cacao" e ingàzeiros. $\mathrm{O}$ cafèzal tinha bom aspecto $\mathrm{e} o$ solo assemelhava-se ao tipo massapê do Estado de São Paulo.

O cafèzal do sítio "Florência", onde foram retiradas as amostras de números 22 a 24, tinha aspecto regular. As árvores estavam mal enfolhadas e o sombreamento era feito com ingàzeiros e Grevillea robusta.

No sítio "El Olvido", de onde retiramos as amostras de números 25 a 27, o cafèzal apresentava-se bom e o sombreamento era feito com ingàzeiros. $O$ solo era fôfo até cêrca de um metro de profundidade, e muito compacto abaixo dessa profundidade. Aparentemente, era muito rico em cinzas.

\section{6 - DISCUSSÃO}

\section{1 - OBSERVAÇס́ES GERAIS}

O sombreamento dos cafèzais em São Paulo tem sido problemático. Das muitas experiências oficiais e várias tentativas particulares feitas, a grande maioria produziu resultados negativos. Várias árvores de sombra foram experimentadas : pisquim, "madre del cacao", ingàzeiros, etc. Tôdas essas e muitas outras são empregadas, na América Central, no sombreamento, com bons resultados. Aqui, entretanto, nenhuma resolveu, até agora, o problema do sombreamento. Não parece, portanto, estar o êxito do sombreamento na simples escolha da árvore de sombra.

Os insucessos no sombreamento em São Paulo foram atribuídos, frequentemente, à poda inadequada das árvores de sombra. Ora, porque teria sido muito intensa; ora, demasiadamente fraca. Vimos na América Cen- 
tral cafèzais com as árvores de sombra podadas das maneiras mais diversas : ora, dràsticamente; ora, apenas muito levemente. Sob tôdas elas, os cafeeiros vegetavam bem.

I'roclamon-se também, entre nós, que o uso da enxada nos cafèzais sombreados é que motivava os fracassos no sombreamento dos cafèzais paulistas, pelo fato de cortar radicelas superficiais dos cafeeiros. Em Costa Rica, fazem a paléa que, como vimos atrás, é uma operação muito mais violenta do que a nossa carpa. Por atingir uma profundidade bem maior, corta maior número de radicclas. Esses fatos parecem mostrar que há fatôres em nosso clima, ou em nosso solo, que interferem na prática do sombreamento dos cafeeiros, pois, do contrário, êsses vegetariam bem aqui como lá, debaixo de qualquer árvore de sombra, eom poda intensa ou fraca, com carpa ou sem carpa, raspando ou não o solo para coroação, debaixo de sombra bastante intensa ou poueo intensa, ete.

\section{2 - DADOS ME'T'EOROLÓGICOS}

Embora não nos tenha sido possível encontrar dados meteorológicos mais completos e em maior número, como seria de desejar, os conseguiłos e constantes no quadro 1 são suficientes para mostrar que os fatôres meteorológicos não explicam a diferenca do comportamento dos cafèzais à sombra na América Central e em São Paulo, como veremos no decorrer dêste capítulo.

O quadro 1 mostra que a distribuição da queda pluviométrica anual pelos diferentes meses do ano, na Meseta Central de Costa Rica e em El Salvador, é menos uniforme do que em Campinas, que pode representar o regime pluviométrico das regiões cafeeiras do Estado de São Paulo. O período sêco anual naquelas regiões é mais prolongado que o do nosso Estado, não podendo, portanto, residir no regime pluviométrico anual a causa de tantos insucessos no sombreamento aqui verificados.

De ig'ual ou de maior importância que a queda pluviométrica total dos diferentes meses, é o número de dias chuvosos de cada mês, ou seja a frequêneia pluviométrica, pois, uma única chuva forte, é menos eficiente do que diversas precipitações de intensidade moderada, totalizando a mesma quantidade de água. Os dados de frequêneia pluviométrica, que se acham no quadro 1, mostram que, nos meses de menor queda pluviométrica, a frequência das chuvas é, na Meseta Central de Costa Rica, comparável à de Campinas, e, em El Salvador, sensivelmente mais baixa. Portanto, também neste fator climático não reside a explicação do comportamento diverso do cafeeiro à sombra naqueles países e em São Paulo.

Os dados de umidade relativa de ar que se encontram no quadro 1 mostram grande semelhança entre as três regiões estudadas. Essa semelhança é ainda maior no período sêco do ano, que é o que mais interessa ao nosso trabalho. Não podemos, portanto, supor que o cafeeiro se comporte diferentemente nessas regiões em consequência de diferenças sensíveis dêsse fator climatológico. 
As médias anuais de temperatura, de Campinas e da Meseta Central de Costa Rica, são bastante semelhantes, conforme podemos ver no quadro 1. Em San Salvador, essa média é um pouco mais elevada do que as das duas primeiras. Considerando-se apenas o período sêco, a diferença de temperatura entre San Salvador e Campinas se acentua um pouco mais, sendo, nesse período, de 5,6 graus centígrados. O período de sêca é, portanto, em San Salvador, um pouco mais quente do que em Campinas. A julgar apenas por êsse fato, as plantas deveriam transpirar mais em San Salvador do que em Campinas, em igualdade de todos os outros fatôres e, portanto, lá necessitariam de maior quantidade de água do que aqui, para o processo de transpiração. $\Delta$ ssim, pois, essa diferença de temperatura, ao invés de explicar, introduz maior complexidade na interpretação do sombreamento em nossas condições.

Considerando-se que um dos fatôres que mais influenciam sôbre a transpiração das plantas e, portanto, sôbre a quantidade de água que elas retiram do solo, é a radiação solar, uma grande diferença entre a nebulosidade das regiões estudadas da América Central e de São Paulo, principalmente durante os meses de sêca, poderia talvez explicar a questão em foco, do sombreamento dos cafèzais. Essa grande diferença, entretanto, não existe, como mostram os dados do quadro 1 .

Vemos que nenhum dos fatôres climáticos estudados explica a razão do sucesso do sombreamento dos eafèzais na América Central e do reduzido êxito com êle obtido no Estado de São Paulo, onde a maioria das experiências e tentativas têm mostrado visível desvantagem nessa prática.

\section{3 - CONSTANTES FÍSICAS DO SOLO}

\subsection{1 - "WILTING POINT" E "MOISTURE EQUIVALENT"}

Nos quadros 2 e 4 vemos os dados de "wilting point" de Costa Rica e El Salvador, respectivamente. Todos os dados dessa constante física, obtidos com os solos de Costa Rica, são bastante elevados, bem mais elevados do que os dos solos paulistas cultivados com café, onde a terra roxa legítima forneceu os valores mais altos, que estão ao redor de $18 \%$ ( 7 ).

Em El Salvador, com exceção dos solos situados nas encostas do vuleão "San Salvador", que são correspondentes às amostras das séries $1,2,9,10$, (quadro 4) ; os valores do "wilting point" são também bastante elevados. Os solos atrás mencionados diferenciam-se dos outros aparentemente, por serem constituídos, em grande parte, de cinzas vulcânicas, ao passo que os outros são bastante argilosos.

A razão "moisture equivalent" para "wilting point" é, em média, para os solos estudados em Costa Rica, de 1,29, com pequena variação em tôrno da média. Para os solos estudados em E1 Salvador, essa relação média é de 1,44 para os solos argilosos e 1,94 para os ricos em cinza vulcânica. Como vemos, não encontramos, para os solos estudados, a mesma razão $\frac{\text { M.E. }}{\text { W.P. }}=1,84$ encontrada por Briggs e Shantz (1). Pelo 
contrário, ela variou bastante com os tipos de solo, concordando com os trabalhos de Veihmeyer e Hendrickson (13) e Duncan (2), que também acharam grande variação nessa relação entre diferentes solos.

\subsection{2. - AGUA DISPONFVEL}

É digno de nota o fato de têrmos encontrado, em todos os lugares estudados, quantidade apreciável, às vêzes surpreendente mesmo, de água disponível às plantas no solo, após vários meses de sêca. Em nossos solos, mesmo em cafèzais cultivados ao sol, portanto, sem a concorrência de árvores de sombra, é pequena a quantidade de água disponível às plantas, depois de alguns meses de sêca. Nos cafèzais sombreados, essa quantidade é menor ainda, sendo de notar que, quando êsses cafèzais se apresentam em mau estado como consequência de sêca prolongada, o que geralmente acontece, o solo se encontra frequentemente no "wilting point", às vêzes, até a um metro de profundidade.

Isso parece não ocorrer na América Central. Os dados obtidos em Costa Rica, e que se acham no quadro 3, mostram percentagem considerável de água disponível em tôdas as amostras de solo coletadas, em diversas localidades e a diferentes profundidades em cafèzais sombreados. As percentagens de água disponível encontradas variaram entre 2,4 e 11,6. Estando a densidade dos solos ao redor da umidade, essas percentagens correspondem a cêrca de 24 e 116 litros de água disponível às plantas em cada metro cúbico de terra, respectivamente. Em El Salvador, onde trabalhamos após quatro meses de sêca, os dados mostram também quantidade apreciável de água disponível, conforme vemos no quadro 5. Em um caso apenas, encontramos o solo no "wilting point" a meio metro de profundidade, mas havia umidade abaixo dessa profundidade. $O$ aspecto do cafèzal era regular, e as plantas pouco enfolhadas.

A máxima quantidade de água disponível encontrada foi no solo do sítio "Montserrat", onde havia $16,9 \%$ a um metro de profundidade, o que corresponde aproximadamente, a 169 litros de água, por metro cúbico de solo, ainda absorvíveis pelas plantas. Aliás, o cafèzal que se encontra nesse solo foi o mais bonito que vimos na América Central. Explica isso, o fato de ter sido o solo da baixada, onde se acha o cafèzal, formado em 1934, por ocasião de uma grande tromba de água que para ali arrastou enorme quantidade de terra rica, tirada da superfície das montanhas circunvizinhas. A riqueza excepcional do solo e a grande reserva de água que encerra, explicam a exuberância da vegetação dos cafeeiros. E de notar também que o sombreamento nesse cafèzal é tão esparso, que os cafeeiros têm a conformação dos nossos, cultivados ao sol, sendo as plantas compactas, com ramos curtos

A existência, após vários meses de sêca, de água disponível às plantas nos solos dos cafèzais sombreados, estudados na América Central, é um fato constatado. Entretanto, a razão de uma economia de água, tão favorável à cultura cafeeira sombreada, deveria ser encontrada em pesquisas comparativas e mais aprofundadas sôbre a parte física daqueles solos e dos nossos, principalmente na parte referente à adsorção da água 
pelos colóides. Assim, por exemplo, seria altamente desejável um estudo comparativo de curvas de tensão da água nos solos da América Central e nos do Estado de São Paulo. possível que, como consequência de uma curva de tensão da água mais fechada, em ângulo mais agudo, as plantas nos solos de São Paulo transpirem livremente, até a umidade do solo atingir o "wilting point", resultando em um consumo rápido da água do solo. Ao contrário, se os solos da América Central tiverem uma curva de tensão da água mais aberta, em ângulo mais obtuso, a absorção e a transpiração das plantas serão mais vagarosas, resultando em um consumo mais lento da água do solo. Embora os solos tenham um "wilting point", isto é, uma percentagem de água, abaixo da qual as plantas não mais conseguem dêle retirar água eficientemente, a água disponível existente parece não ser absorvida pelas plantas com a mesma facilidade desde o "field capacity" até o "wilting point". De acôrdo com os trabalhos de Taylor, Blaney e MacLaughlin e Furr e Taylor, eitados em Kramer (9), e Furr e Reeve (8), há uma faixa de murchamento, por assim dizer, ou "wilting range", como foi chamada por aquêles autores, antes de ser atingido o "wilting point", isto é, a percentagem de umidade encontrada no solo, quando as plantas mostram os primeiros sinais de murchamento, é mais elevada do que a encontrada quando se dá o murchamento final, ou seja, o "wilting point". A partir, portanto, de uma certa percentagem de umidade, acima ainda do "wilting point", começa já a haver um aumento na fôrça com que o solo retém a água contra a absorção pelas plantas. A quantidade de água disponível no solo dentro dêsse "wilting range" é variável com os solos e, em consequência da dificuldade com que as plantas a absorve, a razão de absorção é pequena e insuficiente para manter o crescimento, mas garante a sobrevivência das plantas.

Há grande diferença entre os solos quanto à amplitude do "wilting range", consequência direta das diferenças na configuração das curvas de tensão da água. Erovável que os solos dos cafèzais da América Central, por serem vulcânicos, bastante novos, ricos em argilas altamente peptizadas, tenham um "wilting range" bastante amplo, o que favorece a sobrevivência dos cafeeiros nos períodos longos de sêca.

Essa nossa hipótese não é mera conjetura, pois se baseia principalmente em três fatos: $a$ ) têrmos encontrado bastante água disponível após quatro meses de sêca; $b$ ) terem os cafèzais irrigados de Costa Rica reagido muito favoràvelmente à irrigação; c) os cafeeiros da América Central, no período de sêca, apresentam-se murchos, mas enfolhados, ao passo que os nossos derrubam grande parte, às vêzes, quase mesmo a totalidade de suas fôlhas, o que parece indicar que êles, embora não absorvam água suficiente para manterem as fôlhas túrgidas, a absorvem de forma suficiente para a manutenção da transpiração cuticular das fôlhas murchas.

Não é impossível que, devido aos fatôres acima considerados, o sombreamento seja mesmo de grande vantagem nos solos da América Central; diminuindo a transpiração das plantas, faz com que a pequena quantidade de água que elas conseguem absorver do solo, seja suficiente para a sua sobrevivência nas épocas sêcas. 


\section{7 - CONCLUSÕES}

De nossas observações e dos dados experimentais obtidos, podemos tirar as conclusões seguintes :

a) Os cafèzais da América Central vegetam bem à sombra de diversas árvores, ao contrário do que geralmente acontece em São Paulo.

b) A escolha da árvore de sombra não explica êsse fato, porque lá são empregadas com sucesso, no sombreamento, tôdas as árvores que entre nós têm sido experimentadas sem resultados satisfatórios.

c) Diferenças nos tratos culturais também não explicam a razão do bom desenvolvimento do cafeeiro, à sombra, na América Central. Esses tratos são bastante variáveis naquela região, sendo alguns muito mais drásticos e prejudiciais ao sistema radicular do eafeeiro do que a nossa capina à enxada, tal como a paléa, usada em Costa Rica.

d) A intensidade de sombra adotada pelos cafeicultores centroamericanos é muito variável, e as suas opiniões sôbre o assunto divergem bastante. Tôdas as intensidades aqui tentadas são encontradas nos cafèzais da América Central, não sendo êsse, portanto, o fator de sucesso do sombreamento dos cafèzais centro-americanos.

e) Os estudos climatológicos comparativos mostram que não residem no clima os fatôres que propiciam condições favoráveis ao sombreamento na América Central.

f) Após mais de quatro meses de sêca, a umidade do solo dos cafèzais estudados na América Central estava bem acima do "wilting point", indicando haver ainda bastante água disponível à absorção das plantas, ao contrário, portanto, do que tem sido observado no Estado de São Paulo.

g) A conclusão anterior explica a razão por que os cafeeiros vegetam bem, debaixo das árvores de sombra, nas regiões sujeitas à sệca, na América Central, ao contrário do que geralmente acontece quanto aos cafèzais sombreados do Estado de São Paulo.

h) A razã̃o pela qual os solos estudados na América Central ainda encerram água disponível, após alguns meses de sêca, deveria ser pesquisada em estudos comparativos da parte física, especialmente das curvas de tensão da água, nos solos da América Central e nos do Estado de São. Paulo.

\section{S U M M A R Y}

The coffee plant does not thrive well under shade in most of the coffee areas. of the State of São Paulo, Brazil. It has been shown that water competition from the shade trees during the dry scason is the factor responsible for the failure in growing coffee under shade in Sāo Paulo. In all cases where the coffee plants were not thriving well under shade, the soil moisture after two to thrce months of drought was at the wilting point at the depths most utilised by the root systems of shade trees and coffee plants. In open plantations this was never observed.

All commereial coffee plantations of Central America are shaded. Most of them are located in areas with a dry season as long as in São Paulo and some times even longer. A comparative study of the climatological factors, methods of cultivation and most common species of shade trees was made. No one of these factors explained 
the different behavior of the coffee plant under shade in Central America and in São Paulo.

The available soil water was measured in many coffee plantations in Costa Rica and El Salvador after four months without apreciable rainfall. In all cases it was: found that the actual moisture percentage was considerably higher than the wilting point.

The amount of available water held by soils in São Paulo and Central America does not seem to be significantly different, although this was not carefully determined.

It is suggested that a comparative study of the moisture-tension curves of soils of São Paulo and Central America might explain the different behavior of the coffee plant with shade under these two different conditions. It is possible that, as a consequence of a much steeper moisture-tension curve, the plants in São Paulo soils transpire freely until the soil moisture reaches the wilting point. This would result in a rapid soil water consumption. If the Central American soils have a smoother moisture-tension curve, the water absorption and transpiration rate by plants may be slower and as a consequence the available water may last longer in the soil.

The ratio of the moisture equivalent to the wilting point was found to be around 1.29 for the soils studied in the Meseta Central of Costa Rica, around 1.44 for those in El Salvador and 1.94 for the ashy soils in the vicinity of San Salvador volcano.

\section{LITERATURA CITADA}

1. Briggs, L. J. e H. L. Shantz. A wax seal method for determining the lower limit of available soil moisture. Bot. Gaz. 51: 210-219. 1910.

2. Duncan, W. H. Wilting coefficient and wilting percentage of three forest soils of the Duke Forest. Soil Sci. 48: 413-420. 1939.

3. Franco, C. M. O problema do sombreamento dos cafèzais em São Paulo. Bol. Sup. Serv. Café de S. Paulo 22: 708-717. 1947.

4. Franco, C. M. O problema do sombreamento dos eafèzais em São Paulo. Ceres (Viçosa) 8: 37-51. 1948.

5. Franco, C. M. e H. Godoy. Chuvas e umidade relativa do ar em Campinas, de 1890 a 1945. Bragantia 6: 217-238. 1946.

6. Franco, C. M. e R. Inforzato. O sistema radieular do cafeeiro nos tipos de solo do Estado de São Paulo. Bragantia 6: 443-478. 1946.

7. Franco, C. M. e H. C. Mendes. Ãgua inativa de alguns tipos de solos do Estado de São Paulo. Bragantia 7: 129-132. 1947.

8. Furr, J. R. e J. O. Reeve. The range of soil-moisture percentages through which plants undergo permanent wilting in some soils from semiarid irrigated areas. J. Agr. Res. 71: 149-170. 1945.

9. Kramer, P. J. Em Plant and soil water relationships. MeGraw Hill Book Co., 347 pág., 1. a ed., 1949.

10. Lazo, A. C. Lecciones de Meteorologia Elemental. El Cafe de El Salvador 5: 216-328, 388-396. 1935.

11. Pittier, H. Capitulos Escogidos de la Geografia Fisica y Prehistorica de Costa Rica. Publ. do Museo Nacional de Costa Rica, Série Geográfica. 1 parte: 1-56. 1938.

12. Sapper, K. Em Climatology of Central America. Tradução do original alemão "Klimakunde von Mittel-amerika. Handbuch der Klimatologie, Berlin, 1932" pela U. S. Army Air Corps Weather Service. Editado por U. S. Weather Bureau.

13. Veihmeyer, F. J. e H. A. Hendrickson. The moisture equivalent as a measure of the field capacity of soils. Soil Sci. 32: 181-193. 1931. 